\title{
ACMEORIENTED DEVELOPMENT OF TEACHERS IN THE INTEGRATED EDUCATIONAL SPACE
}

\author{
Mahabbat Taikumanova ${ }^{1}$, Elmira Uteubayeva ${ }^{2}$ \\ ${ }^{1}$ E.A. Buketov Karaganda University, Karaganda, Kazakhstan \\ ${ }^{2}$ E.A.Buketov Karaganda University, Karaganda, Kazakhstan \\ ORCID ID: 0000-0002-1648-114X
}

\begin{abstract}
In this article, the problems of the teacher's professional development, as well as the pedagogical conditions of the acmeoriented mentoring within educational institutions are being examined. The characteristics of mentoring, the features of the integrated educational space of pedagogical education in the training of teachers also had been presented here. Nowadays, the need for mentoring is quite urgent to an extent that a modern teacher must be able to instantly 'react' to the ongoing changes within the educational system. A proper 'response' to such metamorphoses in the institutional environment is required such that it's encompassing alterations of the educational program's content, the introduction of brand-new teaching methods and technologies. Mentoring is organically combining acmeorinted professional development, its personalization, and guarantees a holistic approach to each teacher. It's believed by us that mentoring allows us to expand applied professional skills and competencies. The following paper represents a general experience of the educational mentoring process, in particular, considering the use of mentoring in the advancement of acting teachers' qualifications. An important role plays an innovative project of advanced training courses, "Pro-teaching", established collectively with Karaganda Buketov University and aimed at developing new training programs.
\end{abstract}

\section{INTRODUCTION}

The Kazakhstani educational system has been undergoing transformation associated with several globally- and regionally-linked objective reasons. The majority of these reasons are directly or indirectly actualized by deep alterations in the needs and demands of civilization towards the system and problems of education in Kazakhstan. The professional establishment of a teacher might be considered as one of the most significant stages of his/her career that determines professional success and inclusion in the process of further personal and professional development by the changing socio-professional situation. In this regard, scientists and practitioners are interested in investigating the acmeoriented development of teachers in an integrated education space by using examples of institutional mentoring. The study of the issues of teacher's professional self-determination; professional self-realization in according with his/her/they personal needs, abilities and opportunities; his/her/ their satisfaction with initial professional results in the procession of entering the job; prerequisites to person's open-mindedness to new things, formation of scientific and creative attitude towards the job and issues of personal development as a human [Achinstein B., Fogo B., 2015].

In addition, such direction shows a lack of conceptual research, based on which new changes could be established into the education practice to align it with the modern and future demands of pedagogical education [Malm B., 2009].

The analysis has revealed several problems worth mentioning here and which are actively discussed by the scientific and pedagogical communities:

- Uneven educational development and digitalization process

- The gradual elimination of the children upbringing and development processes from the education

- Changing (harshening) the requirements to teacher's qualification process

- Difficulties in following the principles of the variability of educational programs and standard approaches, educational requirements, and conditions 
Indeed, non-traditional approaches in problem-solving are needed. First, these should be associated with teachers' preparation as key figures in launching and accelerating the educational process.

Unconventional approaches replace known or classical ways due to the temporal and spatial inappropriateness in the modern and constantly developing systems, consciousness, and worldview of the world. These methods must be affordable, effective, targeted, and science-based; such methods can also be linked to the additional professional education of teachers [Erusalimov et al, 2021]. The system of teachers and managers' advanced training of educational organizations has already been changing and adapting to societal needs and requests [Ibănescu A., 2015]. However, it's not enough, and possibly lacking in terms of an enormous regional variation across the educational organization of the Republic of Kazakhstan in funding, technologies, human resources, geographic distance from education centers, the multinational and multilingual composition of students, etc. There is a plethora of options in overcoming the current struggles in promoting the level of professional training competence. Concerning the characteristics and specificities of the institution, its abilities, demands, and resources, these options rely upon quite heavily. So it's worth focusing on the reformation of the mentoring system within educational organizations.

\section{MAIN PART}

In the context of the following study, the professional establishment of a person defines a complex process of acquiring both professional and social roles, as well as the experience under the active engagement with a socio-professional environment. Consequently, at the certain stage of teacher's professional establishment, an acmeoriented development is possible with the use of new methods of mentoring themselves and under the conditions of development and improvement of such modern personality traits as "creative thinking", "innovative thinking", "multitasking". These techniques allow to boost the competitiveness level of a specialist and prepare to be trained as acmeoriented, cross-functional and fully capable set of professional skills, that the modern Kazakhstani market of educational space is so desperate. Mentoring is an educational resource, the meaning of which is currently underestimated. This could be explained by a gradual loss of the traditional "mentoring", "coaching", "tutoring" starting from the 90s of the XX century, as an informal method of education, especially in the case of young professionals and children with special needs. Overall, since then the educational environment has drastically changed, as well as its participants in the educational process. However, the need for an effective transfer of knowledge by experienced teachers to colleagues has remained in demand [Gottschling, Hahn, Maas, Spinath, 2016].

It can be seen that today professional knowledge and extensive experience are known enough unless these are accompanied by universal skills. The world is rapidly changing: the labor market has become challenging; digital education is a new reality; familiar approaches to work, communication between colleagues and students are now virtual and remote. The teacher must be able to adapt to any changes within the educational environment instantly. This educational trend has already been in demand, as well as the adapted teacher equipped with a new set of professional skills (in addition to the knowledge of the subject, meta-subject, and integrated subjects). A new tendency has been spotted in the grading system of a teacher with non-traditional educational parameters. These scores are associated with an international assessment system TIMSS, PISA, PIRLS, that evaluate: the functional literacy of schoolchildren in different parts of the world, ability to apply knowledge in practice, "reading skills", "digital skills", "natural sciences", "semantic reading", "critical thinking and logic", i.e. assessing the basic level of proficiency in soft skills.

On such occasions, that require a dynamic development of the school education, the demand for real professionals has been growing extremely. The role of the mentor teacher and the mentoring itself as an informal type of education at work, i.e. within a familiar education environment and without an interruption of practical activity - is increasing, too.

An implementation of the "Acmeoriented development of teaches in an integrated educational space" indicated that modern technologies (or models) of mentoring are extremely variable: e- and flash-mentoring, speed reading, virtual and self-assessed, reversed coaching, tutoring, storytelling, 
etc. These technologies allow achieving desired outcomes even in the absence of the required amount of resources, insufficient motivation of mentors with the qualifications needed to be changed [Mitescu M., 2014]. Therefore, there are special prerequisites to the personality of the mentor, due to a musthave capability in developing applied professional competencies in their fellows. It is natural to question whether there is a unique human resource in each educational organization that head schools can incorporate into the training and development of pedagogical personnel. In this case, the mentorteacher is a person with a piece of advanced knowledge and experience, who: shares the values, provides emotional supports, guides with the formation of teacher's growth trajectory, might give professional advice, helps with the professional and organizational matters, facilitates access to information resources [Shwartz G., Dori Y.J. 2016]. Based on new approaches and techniques, could a mentor-teacher be able to create a team of a teacher who is: flexible, mobile, competent, all-timelearners, e-educated, IKT, stress-resistant?

It can be noticed that mentors should pass through an educational system and be extremely motivated to acquire new skills and abilities. In the Karaganda region's education system, this approach in mentor's training is currently being prepared for testing. The implementor of the innovative training program for the teacher is the LPP "Pro-teaching". In the process of making this project, special attention has been paid to the identification of difficulties in the mentor teacher's professional activity, ability to set objectives and development of interactive programs. As a result, a mentor-teacher determines the level of professionally significant qualities and creates an adaptive program for teachers. In the process, key pedagogical techniques are incorporated into the program: the pedagogical culture, the culture of the pedagogical self-analysis, the culture of self-improvement, and the culture of professional self-realization. Therefore:

- Structural components of the acmeoriented development (motivation, gnostic, constructive-design, communication, and diagnostic-reflection).

- Criteria of the acmeoriented development (cognitive, active, regulatory, ethical, and creative),

- Levels of acmeoriented development (normative, creative, and innovative).

- Organizationally pedagogical conditions of the mentoring system development:

- The development of sustainable motivation for the teaching profession and the process of actualization in self-knowledge, self-reflection, self-control, self-development, and selfrealization.

- Organization, specification, and formation of professional skills in applying practical knowledge

- Creation of education programs within the framework of teaching training courses.

- Organization of scientific and methodological seminars, courses, webinars to exchange experience.

The participation of teachers in the survey made it possible to analyze personal achievements and identify professional difficulties in terms of indicators, taking into account individual capabilities.

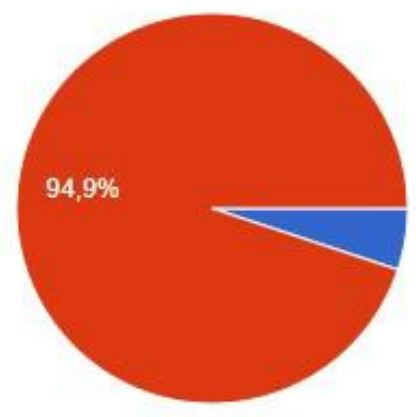

The questionnaire consists of four questions, the answers to which allows obtaining information about the need for advanced training, the areas of professional knowledge and competencies, and the experience of respondents' advanced training. The questionnaire has been compiled and posted in Google Forms. The number of participated respondents in the survey was 14,357 teachers. The analysis showed that $94.7 \%$ of the respondents declare the need for advanced training. 
The respondents would like to improve their qualifications in ICT technologies, project methodology, new teaching methods, rating and accreditation, etc. The most popular answers to the question "What professional competencies would you like to develop?" were ICT, managerial, methodical ones. $78 \%$ of respondents have already had experience of taking advanced training courses remotely.

One of the reasons for taking advanced training courses was the need to master new knowledge and skills, qualification requirements, a sense of the need to acquire new knowledge and

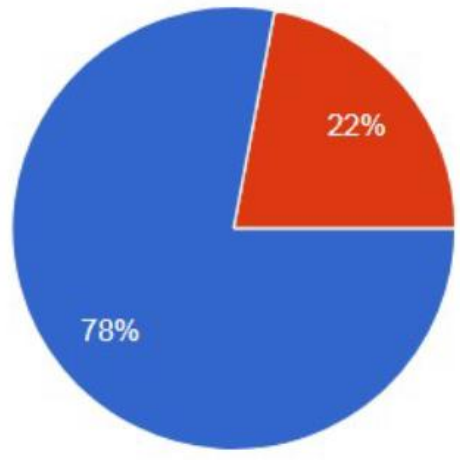
self-realization.

The following educational training programs have been developed and tested:

- Design and research activities. Going beyond the standard solution, developing creative thinking, social interaction. Mastering educational technology, which involves students solving research, the creative problem under the guidance of a specialist, during which the scientific method of cognition is implemented (regardless of the field of study).

- The new concept of teaching a foreign language at school. This seminar includes the analysis of modern approaches in teaching a foreign language (English language) by new conditions and requirements, new approaches to the theory of learning through the development of thinking, and standards of level teaching.

- The XXI century school: modern trends of teaching methods. The course content includes issues of modern teaching methods using web resources, digital learning technologies, and the analysis of the application of new teaching paradigms

- Modern school and attestation: criteria and quality indicators. The course of the seminar covers criteria and indicators of the quality of education, tools for measuring quality at the institutional level, and the level of requirements for enhancing the quality of disciplines. Quality metrics analysis, monitoring, and evaluation system, and teaching quality requirements are also discussed.

- Level training of a foreign language at school: implementation of international standards. The content of the course includes issues of international standards for level teaching and analysis of the quality of teaching foreign languages at school. The issues of introducing a systemic transition to world practices to improve the learning of foreign languages are also considered.

- Accreditation and rating of educational programs: analysis for further improvement of indicators. Analysis of indicators of accreditation and rating quality indicators, a monitoring system for quality improvement, requirements for teaching quality.

- How to effectively manage the university: system-based approach. The content of the course includes issues of internal and external quality, the development of a systematic approach to monitoring quality assurance and development, quality assessment issues.

- Strategies for developing the quality of higher education: quality assurance and management. The course of the seminar covers the criterion and indicators of the quality of education, tools for measuring quality at the institutional level and at the level of educational programs, including requirements for ensuring the quality of the taught disciplines.

The substantive conditions created during the passage of the aforementioned advanced training courses contributed to the development of the design stage. This is aimed at shaping teachers' needs in designing acmeoriented development, in improving knowledge, skills, and abilities acquired in the seminars. As a result, completion and diagnostics via Google Form questionnaires provided an 
opportunity in solving problems such as problematic, inversive, contributing to flexibility and authenticity, and group work.

\section{RESEARCH METHODS}

The scientific publications, reports, personal database in the field of mentoring in educational organizations with the aim of continuous, acme-oriented professional education of teachers were used in the research. The following research methods were used: analysis of theoretical sources, systematization of material, analysis, classification, generalization. Also, the analysis of international and Kazakhstani experience of mentoring in educational organizations, the results of the implementing project were used in the research.

\section{CONCLUSION}

Thus, the implementation of the project "Acmeoriented development of teachers in an integrated educational space" showed that the developed programs within the framework of advanced training courses will allow teachers - mentors:

- to develop management skills;

- to expand theoretical training;

- to get practical skills of mentors;

- to analyze your ideas about the levels of professional competence of a teacher;

- to develop an acme-oriented path of the teacher's development.

Mentoring has a huge impact on the formation of a young teacher: it contributes to the formation of a professional personality, self-realization and self-improvement. With the help of a mentor, the effectiveness of this condition helps the administration in an educational institution quickly and efficiently, solve the problems of professional development of novice teachers, namely, provide assistance in difficult moments, give recommendations, share their experiences. It is expected that questions and solutions may be elevated in the process of the research implementation. The methodological approaches, forms of training, periods of testing and implementation will be developed.

\section{REFERENCES:}

Achinstein B., Fogo B. (2015). Mentoring novices' teaching of historical reasoning: Opportunities for pedagogical content knowledge development through mentor-facilitated practice // Teaching and Teacher Education. Vol. 45. P. 45-58. DOI: http://dx.doi.org/10.1016/.2014.09.002

Erusalimov, R., Stoykova, P., Nestorov, L., Panteleeva, I., Marinov, M. (2021). Increasing the financial literacy and economic culture of students in grades 5-10. ISBN 978-954-23-1948-1, D.A. Tsenov Academy of Economics, Svishtov

Gottschling J., Hahn E., Maas H., Spinath F. M. (2016). Explaining the relationship between personality and coping with professional demands: Where and why do optimism, self-regulation, and selfefficacy matter? Personality and Individual Differences, vol. 100, pp. 49-55. DOI: https://doi.org/10.1016/j.paid.2016.03.085

Ibănescu A. (2015). How Do Novice Specialists in Human Resources Develop their Professional Identity? Procedia - Social and Behavioral Sciences, vol. 187, pp. 596-600. DOI: https://doi.org/10.1016/j.sbspro.2015.03.111

Malm B. (2009). Towards a new professionalism: enhancing personal and professional development in teacher education, Journal of Education for Teaching, 35:1, 77-91, DOI: $\underline{10.1080 / 02607470802587160}$

Mitescu M. (2014). How do Beginning Teachers Employ Discursive Resources in Learning and Affirming their Professional Identity? // Procedia - Social and Behavioral Sciences. Vol. 128. P. 29-35. DOI: http://dx.doi.org/10.1016/j.sbspro.2014.03.113

Shwartz G., Dori Y.J. (2016). Looking through the Eyes of Mentors and Novice Teachers: Perceptions Regarding Mentoring Experiences // Procedia - Social and Behavioral Sciences. Vol. 228. P. 149-153. DOI: http://dx.doi.org/10.1016/j.sbspro.2016.07.022 